\title{
Coaptation of Cutaneous Nerves for Intractable Stump Pain and Phantom Limb Pain after Upper Limb Amputation
}

\author{
Hideki Kadota ${ }^{1}$, Kunihiro Ishida ${ }^{2}$
}

\begin{abstract}
Background: Various surgical treatments have been advocated for stump pain and phantom limb pain after limb amputation but the most effective is unknown. We report a case of intractable stump pain and phantom limb pain of the upper limb, which was successfully treated by end-to-end coaptation of the cutaneous nerves after multimodal treatment failures.

Case description: A 39-year-old man was referred to our department with a history of severe stump neuroma-related pain and phantom limb pain of his right upper limb. He had undergone multiple treatments over 26 years including medication, nerve blocks, and repeated surgeries. None had been successful for relief of pain. The clinical assessment showed a point of marked tenderness around the medial stump of the upper arm. Ultrasound-guided peripheral infiltration of local anaesthetic around the medial stump produced significant relief of his pain. Exploration around the medial limb stump revealed two stump neuromas of the medial cutaneous nerves of the forearm. Both stump neuromas were resected, and their stumps were coapted to each other. After 4 years, he was completely relieved of his pain and without any sensory deficit. Conclusion: Successful nerve coaptations for painful stump neuromas of the upper limb are reported rarely. This case suggests this method can be helpful. The patient burden was minimal because it involved the resection and coaptation of the two neuromas. This method should be encouraged for cases of intractable stump-related pain in the upper limb.

Keywords: Cutaneous nerve, End-to-end coaptation, Phantom limb pain, Stump neuroma, Stump pain.

Strategies in Trauma and Limb Reconstruction (2020): 10.5005/jp-journals-10080-1442
\end{abstract}

\section{BACKGROUND}

Multimodal treatments for neuroma-related stump pain and phantom limb pain after limb amputations have been reported. In recent years, nonsurgical treatments such as neuropathic pain medications, nerve blocks, ${ }^{1}$ or radiofrequency ablation ${ }^{2,3}$ have been selected as the initial treatment. However, those treatments may not successfully relieve pain ${ }^{4}$ and some patients require surgical intervention. There are various kinds of surgeries for neuromarelated stump pain: simple ligation, ${ }^{5}$ capping the nerve stump, ${ }^{6}$ centrocentral nerve coaptation, ${ }^{7-10}$ and implantation of the nerve stump into the surrounding vascularized tissue. ${ }^{11-24}$ However, the failure rate of surgical intervention of up to $65 \%$ has been reported. ${ }^{21-24}$ Among various surgical treatments, we assume that nerve-to-nerve coaptation creates an ideal physiologic state and can prevent recurrence of the neuroma because the stump of the nerve would be sealed by the healthy epineurium and can recover in a normal environment.

We report a case of successful surgical treatment of intractable neuroma-related stump pain and phantom limb pain after upper limb amputation by resecting the two stump neuromas of medial cutaneous nerves of the forearm followed by end-to-end nerve coaptation. This surgery has been applied rarely in the upper limb. Surgical details and outcomes of this method are presented.

\section{Case Description}

A 39-year-old man with a history of severe stump pain and phantom limb pain of his right upper limb for over 26 years was referred to our department. He had undergone a right below-elbow amputation when he was 13 years old because of severe avulsion injury of his forearm. Six years later, he developed phantom limb pain and stump
${ }^{1}$ Department of Plastic Surgery, Kyushu University Hospital, Fukuoka, Japan

${ }^{2}$ Department of Plastic and Reconstructive Surgery, Okinawa Chubu Hospital, Okinawa, Japan

Corresponding Author: Hideki Kadota, Department of Plastic Surgery, Kyushu University Hospital, Fukuoka, Japan, Phone: +81-92-642-5668, e-mail: hkadota@hotmail.co.jp

How to cite this article: Kadota H, Ishida K. Coaptation of Cutaneous Nerves for Intractable Stump Pain and Phantom Limb Pain after Upper Limb Amputation. Strategies Trauma Limb Reconstr 2020;15(1): 50-53.

Source of support: Nil

Conflict of interest: None

pain. The pain was diagnosed as neuroma-related pain and he underwent excision of the stump neuromas of the radial, ulnar, and median nerve three times. Despite repeated surgeries, the pain was only relieved partially and temporarily and became more intense after the surgeries. After the last surgery, the pain was treated by nerve blocks but the effect transient.

At first assessment in our unit, he presented with increased and intolerable phantom pain and stump pain. He described the pain as stabbing with an intensity of $9 / 10$ on the visual analogue scale. The pain lasted for a few minutes and reoccurred at 30-60 minute intervals. It was accentuated when pressure was applied to the medial side of the limb stump (Fig. 1) and the Tinel's sign was confirmed by pressing on the point. He experienced phantom pain and sensations on his small and ring fingers. Oral administration of pregabalin, opioids, and non-steroidal anti-inflammatory drugs

() The Author(s). 2020 Open Access This article is distributed under the terms of the Creative Commons Attribution 4.0 International License (https://creativecommons. org/licenses/by-nc/4.0/), which permits unrestricted use, distribution, and non-commercial reproduction in any medium, provided you give appropriate credit to the original author(s) and the source, provide a link to the Creative Commons license, and indicate if changes were made. The Creative Commons Public Domain Dedication waiver (http://creativecommons.org/publicdomain/zero/1.0/) applies to the data made available in this article, unless otherwise stated. 


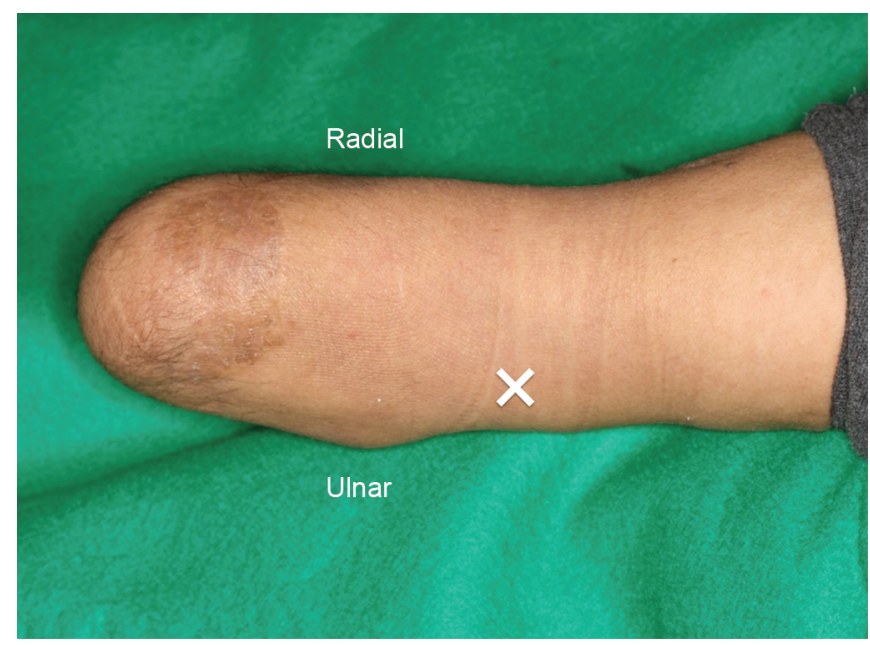

Fig. 1: Appearance of the right upper extremity and the point of severe stabbing pain (marked as a white cross)

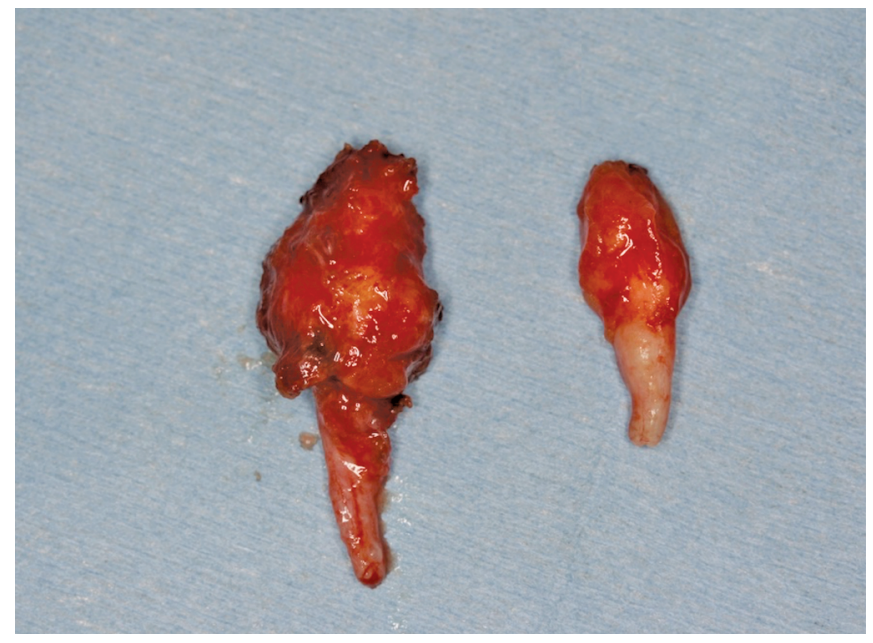

Fig. 3: Resected stump neuromas of the medial cutaneous nerve of forearm

and a stellate ganglion block injection were ineffective. He could no longer use his upper limb prosthesis because of this severe stump pain.

An ultrasound examination showed that the stump of the ulnar nerve was around the point of pressure-induced pain. Infiltration of local anaesthetic of $1 \%$ lidocaine around the ulnar nerve stump with ultrasound guidance produced significant pain relief. This suggested that the pain was possibly related to the problem around the stump of the ulnar nerve.

Surgical exploration around the medial side of the upper limb was performed. Two large stump neuromas originating from the medial cutaneous nerve of the forearm were found (Fig. 2). The tight scar tissue had formed around the stump neuromas making dissection very difficult. The nerve stump of the ulnar nerve was found close to the stump neuromas of the medial cutaneous nerve of the forearm but had not developed into a stump neuroma. The nerve stumps of median and radial nerves were also explored but none had developed neuromas and all were free of scarring. Neuromas that had developed in the stumps of the medial cutaneous nerves of the forearm were considered to be the main cause of his pain and both resected (Fig. 3). After confirming that

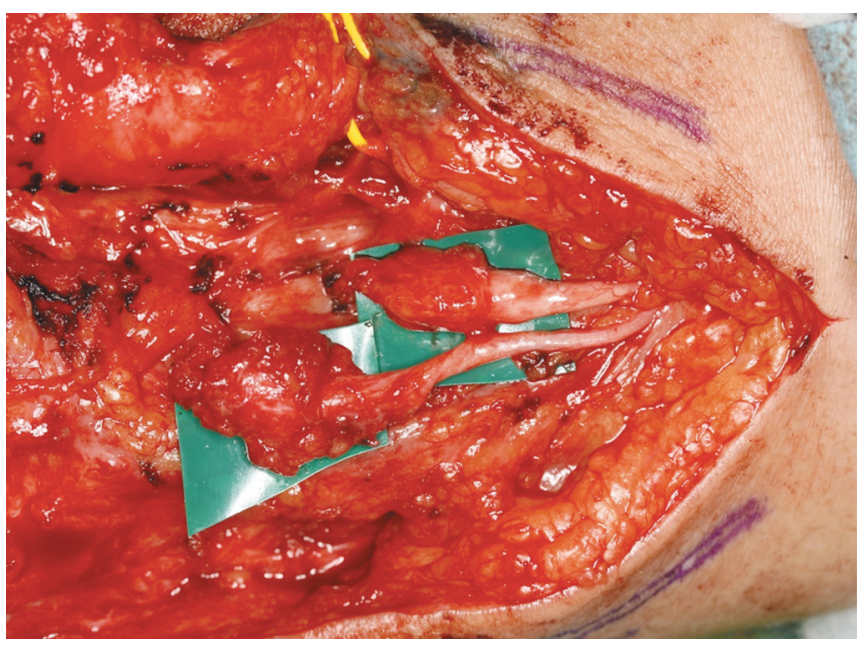

Fig. 2: Stump neuromas of the medial cutaneous nerve of the forearm with severe scarring

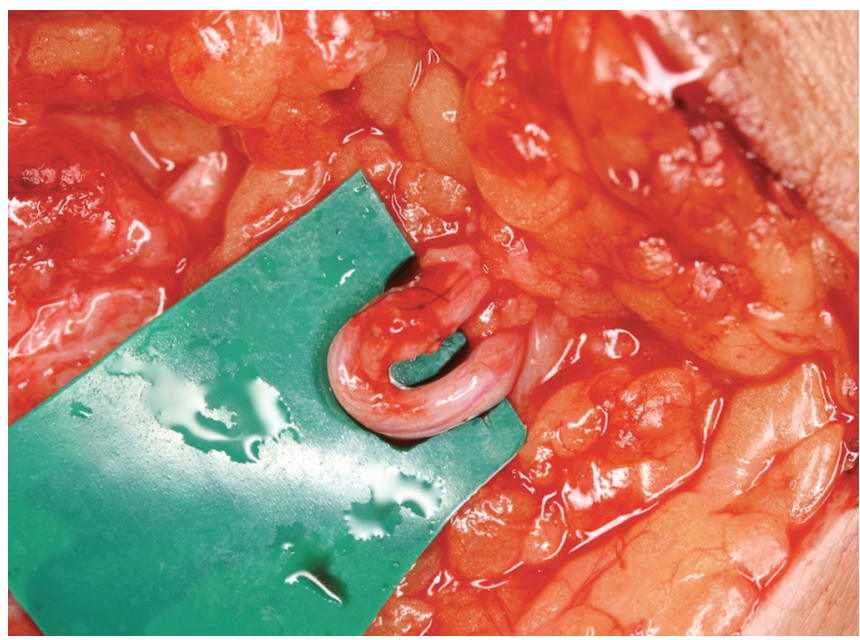

Fig 4: End-to-end coaptation after resection of the stump neuromas

the cut ends of the medial cutaneous nerves were healthy and with clear fascicles and no scar tissue, the ends were coapted together in an end-to-end fashion using \#9-0 nylon without any tension (Fig. 4).

After surgery, the patient's stump pain and phantom pain diminished dramatically. Four years after the surgery, the patient has only occasional episodes of stump or phantom pain with symptoms only when it rained, describing the intensity of pain as $3 / 10$ on the visual analogue scale and with a duration of only a few minutes. There was no longer a need for oral analgesics or nerve blocks and the patient has been using his upper limb prosthesis without problems.

\section{Discussion}

Stump neuroma-related pain occurs in $13-32 \%$ of patients after limb amputation. ${ }^{25-28}$ The incidence of phantom limb pain is reportedly higher, up to $80 \%$ after amputation. ${ }^{29,30}$ Amputation stump pain should be distinguished from phantom limb pain but this is difficult to do sometimes. ${ }^{31}$ There is growing consensus that the two types of pain are caused by a problem of not only the peripheral nerve but also the central nervous system and they are intimately related to each other. The exact aetiology of neuroma-related stump pain and 
phantom limb pain is still poorly understood and their treatments are controversial.

Various surgical interventions for neuroma-related pain and phantom limb pain have been described, which differ in the way the stump of the responsible nerve is managed. In most cases, the stump neuroma is resected and the cut end of the nerve is coapted to the well-vascularized tissues. The methods of coaptation of the nerve stump vary: to the same nerve (end-to-side or end-to-end anastomosis after nerve split), ${ }^{7,32}$ to a concomitant nerve, ${ }^{8-10,31,33}$ to muscle, ${ }^{4,12,14,18,21,22,24}$ vein, ${ }^{13,16,22}$ fat, $^{19,20}$ or to bone. ${ }^{11,15,17}$ The implantation of the stump into the muscle is the most commonly selected procedure in clinical practice. ${ }^{4}$ However, the results of muscle implantation are variable and the success rate ranges from 35 to $90 \% .{ }^{21-24,34}$ In addition, it is reported that muscle implantation does not prevent neuroma formation but results in the formation of a "non-classical neuroma"; this has no interaction with the muscle fibres and contains small regenerating units of immature nerve fibres in a connective tissue-poor environment. ${ }^{21}$ Thus, the nerve stump implanted into the muscle is in a nonphysiologic state and harmful scarring, irritation and inflammation, and, we suspect, neuroma recurrence may occur.

In reconstructive plastic surgery, there is a principle that "one should reconstruct like tissues if at all possible." ${ }^{\prime 2}$ Ideally, the nerve stump should be coapted to the nerve. In contrast to muscle implantation, the nerve stump can be sealed by the regenerated epineurium in nerve-to-nerve coaptation and thus returned to a physiologic state. The epineurium is considered to work as a shock absorber and protects the axons from damage. ${ }^{34}$ Thus, the risk of recurrence of neuroma would probably be reduced as much as possible after the nerve stump is sealed by the epineurium. So far, success rates of $\geq 90 \%$ for nerve coaptations performed for amputation stump-related pain have been reported, which is higher than that for muscle implantation. 9,31,33

End-to-end nerve coaptation was first applied for painful digital neuromas of the hand by Gorkisch, known as the "Gorkisch pinch," in $1984 .^{10}$ Nowadays, it is mostly performed for major nerves after lower limb major amputation, such as sciatic, tibial, and peroneal nerves. ${ }^{9}$ As mentioned by Elliot, ${ }^{35}$ this method has not been applied to many upper limb cases. Furthermore, this procedure has rarely been performed for cutaneous nerves of the forearm.

Our patient complained of phantom limb pain in his small and ring fingers and so the ulnar nerve was suspected to be the responsible nerve preoperatively. However, surgery revealed no stump neuroma of the ulnar nerve. Only two medial cutaneous nerves of the forearm showed neuroma formation with severe scarring of the surrounding tissue. Although infiltration of local anaesthesia around the stump of the ulnar nerve was effective, this anaesthetic may have been infiltrated around the medial cutaneous nerves of the forearm because of the close proximity of the ulnar nerve and the medial cutaneous nerves in the forearm. The resections of neuromas and coaptation of these cutaneous nerves were effective in relieving both the stump pain and phantom pain. By managing the abnormal peripheral nerves by nerve-to-nerve coaptation, and perhaps before structural changes took place in the central nervous system, success was achieved in a difficult problem.

In recent years, nonsurgical treatments are favoured over surgery for stump pain and phantom limb pain. However, there are still some cases in which pain is refractory to multimodal conservative treatment. Although surgical intervention was required in this patient, there was no sensory nerve deficit after the operation because only two stump neuromas of the cutaneous nerves were handled.

A successful outcome of cutaneous nerve coaptation in the upper limb with long-term follow-up is rare. Although our experience is limited to a single case, it serves to remind surgeons that this method is a useful option as it is simple and minimally invasive. Further accumulation of data on patients managed using this technique should be encouraged to evaluate its overall effectiveness.

\section{Conclusion}

A case of intractable neuroma-related pain of the upper limb was successfully treated by resecting stump neuromas and end-to-end nerve coaptation. Although this method was rarely adapted in the upper limb, its use should be encouraged for cases of intractable neuroma-related pain.

\section{Acknowledgment}

The authors thank Yasunori Sashida for his support in reviewing this article.

\section{Compliance with Ethical Standards}

\section{Ethical Approval}

All procedures performed in studies involving human participants were in accordance with the ethical standards of the institutional and/or national research committee and with the 1964 Helsinki Declaration and its later amendments or comparable ethical standards.

\section{Informed Consent}

Informed consent was obtained from all the individual participant included in the study.

\section{References}

1. Chabal C, Jacobson L, Russell LC, et al. Pain response to perineuromal injection of normal saline, epinephrine, and lidocaine in humans. Pain 1992;49(1):9-12. DOI: 10.1016/0304-3959(92)90181-a.

2. Restrepo-Garces CE, Marinov A, McHardy P, et al. Radiofrequency ablation: pulsed radiofrequency under ultrasound guidance for persistent stump-neuroma pain. Pain Pract 2011;11(1):98-102. DOI: 10.1111/j.1533-2500.2010.00398.x.

3. Tamimi MA, McCeney MH, Krutsch J. A case series of pulsed radiofrequency treatment of myofascial trigger points and scar neuromas. Pain Med 2009;10(6):1140-1143. DOI: 10.1111/j.15264637.2009.00646.x.

4. Pet MA, Ko JH, Friedly JL, et al. Does targeted nerve implantation reduce neuroma pain in amputees? Clinics Orthop Relat Res 2014;472(10):2991-3001. DOI: 10.1007/s11999-014-3602-1.

5. Gonzalez-Darder J, Barbera J, Alamo J, et al. Fascicular ligation in the prevention and treatment of painful terminal neuroma: an experimental study in the rat. Neurosurgery 1987;21(2):215-217. DOI: 10.1227/00006123-198708000-00014.

6. Robbins TH. Nerve capping in the treatment of troublesome terminal neuromata. Br J Plast Surg 1986;39(2):239-240. DOI: 10.1016/00071226(86)90089-5.

7. Barbera J, Albert-Pamplo R. Centrocentral anastomosis of the proximal nerve stump in the treatment of painful amputation neuromas of major nerves. J Neurosurg 1993;79(3):331-334. DOI: 10.3171/jns.1993.79.3.0331. 
8. Belcher HJ, Pandya AN. Centro-central union for the prevention of neuroma formation after finger amputation. J Hand Surg $\mathrm{Br}$ 2000;25(2):154-159. DOI: 10.1054/jhsb.2000.0372.

9. Wood VE, Mudge MK. Treatment of neuromas about major amputation stump. J Hand Surg Am 1987;12(2):302-306. DOI: 10.1016/ s0363-5023(87)80297-6.

10. Gorkisch K, Boese-Landgraf J, Vaubel E. Treatment and prevention of amputation neuromas in hand surgery. Plast Reconstr Surg 1984;73(2):293-296. DOI: 10.1097/00006534-198402000-00027.

11. Goldstein SA, Sturim HS. Intraosseous nerve transposition for treatment of painful neuromas. J Hand Surg Am 1985;10(2):270-274. DOI: 10.1016/s0363-5023(85)80120-9.

12. Hazari A, Elliot D. Treatment of end-neuromas, neuromas-incontinuity and scarred nerves of the digits by proximal relocation. J Hand Surg Br 2004;29(4):338-350. DOI: 10.1016/j.jhsb.2004.01.005.

13. Herbert TJ, Filan SL. Vein implantation for treatment of painful cutaneous neuromas: a preliminary report. J Hand Surg $\mathrm{Br}$ 1998;23(2):220-224. DOI: 10.1016/s0266-7681(98)80178-2.

14. Mackinnon SE, Dellon AL, Hudson AR, et al. Alteration of neuroma formation by manipulation of its microenvironment. Plast Reconstr Surg 1985;76(3):345-353. DOI: 10.1097/00006534-198509000-00001.

15. Mass DP, Ciano MC, Tortosa R, et al. Treatment of painful hand neuromas by their transfer into bone. Plast Reconstr Surg 1984;74(2):182-185. DOI: 10.1097/00006534-198408000-00002.

16. Mobbs RJ, Vonau M, Blum P. Treatment of painful peripheral neuroma by vein implantation. J Clin Neurosci 2003;10(3):338-339. DOI: 10.1016/ s0967-5868(03)00010-9.

17. Chiodo CP, Miller SD. Surgical treatment of superficial peroneal neuroma. Foot Ankle Int 2004;25(10):689-694. DOI: 10.1177/107110070402501001.

18. Adani R, Tarallo L, Battiston B, et al. Management of neuromas in continuity of the median nerve with the pronator quadratus muscle flap. Ann Plast Surg 2002;48(1):35-40. DOI: 10.1097/00000637200201000-00005.

19. Strickland JW, Idler RS, Lourie GM, et al. The hypothenar fat pad flap for management of recalcitrant carpal tunnel syndrome. J Hand Surg Am 1996;21(5):840-848. DOI: 10.1016/S0363-5023(96)80201-2.

20. Rose EH, Norris MS, Kowalski TA, et al. Palmaris brevis turnover flap as an adjunct to internal neurolysis of the chronically scarred median nerve in recurrent carpal tunnel syndrome. J Hand Surg Am 1991;16(2):191-201. DOI: 10.1016/S0363-5023(10)80096-6.

21. Dellon AL, Mackinnon SE. Treatment of the painful neuroma by neuroma resection and muscle implantation. Plast Reconstr Surg 1986;77(3):427-438. DOI: 10.1097/00006534-19860300000016.
22. Balcin $H$, Erba $P$, Wettstein $R$, et al. A comparative study of two methods of surgical treatment for painful neuroma. J Bone Joint Surg Br 2009;91(6):803-808. DOI: 10.1302/0301-620X.91B6.22145.

23. Rose J, Belsky MR, Millender LH, et al. Intrinsic muscle flaps: the treatment of painful neuromas in continuity. J Hand Surg Am 1996;21(4):671-674. DOI: 10.1016/S0363-5023(96)80024-4.

24. Dellon AL, Aszmann OC. Treatment of superficial and deep peroneal neuromas by resection and translocation of the nerves into the anterolateral compartment. Foot and Ankle Int 1998;19(5):300-303. DOI: 10.1177/107110079801900506.

25. Ebrahimzadeh $\mathrm{MH}$, Fattahi AS. Long-term clinical outcomes of Iranian veterans with unilateral transfemoral amputation. Disabil Rehabil 2009;31(22):1873-1877. DOI: 10.1080/09638280902810968.

26. Ebrahimzadeh $\mathrm{MH}$, Hariri S. Long-term outcomes of unilateral transtibial amputations. Mil Med 2009;174(6):593-597. DOI: 10.7205/ milmed-d-02-8907.

27. Geraghty TJ, Jones LE. Painful neuromata following upper limb amputation. Prosthet Orthot Int 1996;20(3):176-181. DOI: 10.3109/03093649609164440.

28. Nelson AW. The painful neuroma: the regenerating axon versus the epineural sheath. J Surg Res 1977;23(3):215-221. DOI: 10.1016/00224804(77)90024-5.

29. Parkes $C M$. Factors determining the persistence of phantom pain in the amputee. J Psychosom Res 1973;17(2):97-108. DOI: 10.1016/00223999(73)90010-x.

30. Sherman RA, Sherman CJ, Parker L. Chronic phantom and stump pain among American veterans: Results of a survey. Pain 1984;18(1):83-95. DOI: 10.1016/0304-3959(84)90128-3.

31. Prantl L, Schreml S, Heine N, et al. Surgical treatment of chronic phantom limb sensation and limb pain after lower limb amputation. Plast Reconstr Surg 2006;118(7):1562-1572. DOI: 10.1097/01. prs.0000233048.15879.0e.

32. Ashely L, Stallings JO. End-to-side nerve flap for treatment of painful neuroma: a 15-year follow-up. J Am Osteopath Assoc 1988;88(5): 621-624.

33. Economides JM, DeFazio MV, Attinger CE, et al. Prevention of painful neuroma and phantom limb pain after transfemoral amputations through concomitant nerve coaptation and collagen nerve wrapping. Neurosurgery 2016;79(3):508-513. DOI: 10.1227/ NEU.0000000000001313.

34. Watson J, Gonzalez M, Romero A, et al. Neuromas of the hand and upper extremity. J Hand Surg Am 2010;35(3):499-510. DOI: 10.1016/ j.jhsa.2009.12.019.

35. Elliot D. Surgical management of painful peripheral nerves. Clin Plastic Surg 2014;41(3):589-613. DOI: 10.1016/j.cps.2014.03.004. 